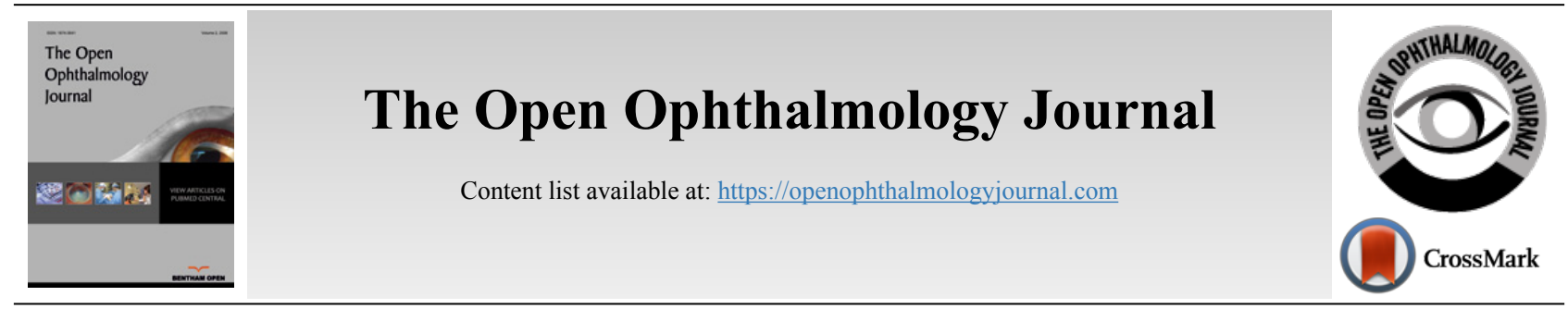

PERSPECTIVE ARTICLE

\title{
Nano Silver Coated Surgical Apparels and Phaco Needles for Safety of Ophthalmic Surgeons in View of COVID-19 Pandemic
}

\author{
Santosh Dnyanmote ${ }^{1, *}$, Jorge Alio ${ }^{2}$ and Anuradha Dnyanmote ${ }^{3}$ \\ ${ }^{\prime}$ Dnyanmote Multispeciality Clinic, Department of Ophthalmology, Pawar Nagar, India \\ ${ }^{2}$ Vissum Innovation, Department of Ophthalmology, Alicante, Spain \\ ${ }^{3}$ Patil Medical College, Pimpri-Chinchwad, India
}

\begin{abstract}
:
Background:

In view of the recent outbreak of the pandemic caused by novel corona virus 19 (n-covid) which has thrown the overall healthcare system that has created fear, apprehension and anxiety amongst all surgeons. Ophthalmic surgeons are no exceptions. The new corona virus is a respiratory virus of the Coronoviridae family containing a single strand of RNA which spreads primarily through droplets generated when an infected person coughs or sneezes or through droplets of saliva or discharge from the nose. A person can get infected by the virus if the person is within 1 meter of a person with COVID 19 or by touching contaminated surface and then touching eyes, nose or mouth.

\section{Methods:}

Standard recommendations to prevent the spread of COVID-19 include frequent cleaning of hands using alcohol based hand rubs or soap and water. Covering the nose and mouth with a proper mask, covering skin, eyes, hair, hands and legs with proper apparel is important.

Just like elderly members of the society, the healthcare workers who have some co-morbidity are susceptible to COVID-19 invasion.

Asymptomatic carriers who may present with senile or pre-senile cataract can be a potential source of infection to other patients, hospital staff, surgeons and others.

Conclusion:

It is important that all the microsurgical instruments which will be used for phacoemulsification be properly sterilized. The surfaces of these instruments should remain free of contaminants as these instruments will be used multiple times in other patients as well.
\end{abstract}

Keywords: Nano silver particles, Phaco needle, Dialers, Choppers, Droplets, Respiratory virus.

\section{Article History}

Received: June 24, 2020

Revised: October 15, 2020

Accepted: November 01, 2020

\section{AIM}

To explore the possibility of providing the healthcare workers the advantanges of using apparels like face masks, surgeons gowns, shoe covers made for multilayered fabric wherein the outer and inner layers will be made of Nano silver impregnated textile and middle layer made of Polytetrafluoroethylene + Polypropylene membrane for impeccable protection to them and creating titanium phaconeedles coated with film made up of titanium dioxide doped Nitrogen and nano silver.

\section{INTRODUCTION}

This paper explores the possibility of using nano silver par-

\footnotetext{
* Address correspondence to this author at Dnyanmote Multispeciality clinic, Ophthalmology 4, Damodar heights, Pawar Nagar, India; Tel: +919923760909; E-mail: sdnyanmote2013@gmail.com
}

ticles doped microsurgical instruments, phaco needles and apparels like surgeons' gown, caps and mask during ophthalmic surgery. A lot of research has been carried out globally on bactericidal and viricidal properties of nano silver particles [1,2]. This paper is presented with the aim of utilizing these properties of nano silver to create surgical apparels and micro instruments. It is a widely known fact that nano silver is highly effective against a number of bacteria, fungi and viruses $[3,4]$. There is enormous amount of material available in public domain which have antibacterial, antifungal and antiviral properties of nanosilver. These properties have been successfully harnessed in food, textile, and pharmaceutical industries.

Textile industry has created apparels for the sportspersons using nano silver impregnated fibers which exhibit 
antibacterial activity and antifungal activity. This prevents skin infections amongst the sports persons as they sweat profusely [5].

One of the recent publications by Muhammad Akhsin and Marcel Frommelt and others conducted jointly by Dept. of Mechanical and Industrial engineering, Gadjah Mada University, Indonesia and University of Stuttgart, Germany reported the use of $\mathrm{TiO} 2(\mathrm{~N}) / \mathrm{Ag} / \mathrm{TiO} 2(\mathrm{~N})$ sandwich film coating which exhibited antibacterial, antifungal and antiviral properties under visible light.

Since the phaco needles and micro surgical instruments are made of titanium it appears to me that if these instruments are coated with this kind of film then these instruments will be safe even before they are put in autoclave for next sterilization cycle [6].

The phaco needles are mounted on a hub provided on the handpiece by screwing it tight with the help of a wrench. The phaco needle is made to vibrate at the preset frequency and the oscillatory movement along with the emitted ultrasound energy emulsify the cataractous lens.

Microsurgical instruments like dialer and choppers aid in cracking and chopping the nuclear fragments. Hence it may be prudent to coat them with this film [7].

Ming-Show Wong and others have reported antibacterial properties of $\mathrm{Ag}$ nanoparticle impregnated Nitrogen doped titania films under visible light in their work published in 2015 $[4,5]$.

They have demonstrated that photocatalysts produce free radicals upon receiving light energy. Silver $(\mathrm{Ag})$ is an antibacterial and antiviral material that disrupts the cellular structures of these microorganisms. They have reported high antibacterial and antiviral property of silver nanoparticles on the surfaces of visible light responsive nitrogen doped $\mathrm{TiO} 2$ photocatalysts could be further enhanced by visible light illumination. In our case, the visible light from the microscope can serve the same purpose. The authors have successfully proved that $\mathrm{TiO} 2(\mathrm{~N}) / \mathrm{Ag} / \mathrm{TiO} 2(\mathrm{~N})$ sandwich films in which the silver is embedded between two layers of titanium dioxide markedly increase the durability of the parent metal.

Their experiments have shown antibacterial action against E.Coli, S. pyogenes, S. aureus and Acinetobacter baumanii by altering their DNA/RNA material.

Nano scale silver particles have emerged as novel antibacterial and antiviral agents to which they can develop resistance albeit only after repeated exposure to nano silver because of the unique chemical and physical properties of nano silver.

Nanotechnology is an emerging field of applied science and cutting edge technology that utilizes physico-chemical properties of nano materials as a mean to control their size, surface area and shape in order to generate different nanoscale sized materials.

Amongst such materials, nanoscale silver is of particular interest because historically silver has been extensively used to treat skin infections, burns, gonococcal infections etc.

\section{METHODS}

This paper has been written after extensive study of scientific data available in public domain on the topic of concern. As mentioned earlier, this paper attempts to explore the possibility of creating a new application based on the works and results published by scientific community on the use of nano-silver impregnated textile fibers to create apparels that exhibit antimicrobial activity. We believe that apparels like face masks, caps, surgeons gowns, shoe covers and other such items should be made using nano silver impregnated textile material. Herein we propose that all these items be multilayered sandwich whose outer and inner layers will be of nano silver impregnated textile and middle layer to be made of PTFE + PP (Polytetrafluoroethylene + Polypropelene) membrane. Although extensive research was made to study as many publications available in public domain as possible we chose to present only those works which are most relevant to our cause. Following are just a few prominent works from where we derive our inspiration.

- Ionic silver textile products and their effects on skin microbes. Author: Lorraine Marchand

- Antibacterial properties of biologically synthesized silver nano particles (AgNPs) by Joanna Chojniak, Lukasz Jalowiecki, Isabella Biedron et al

- Antimicrobial yarn having nano silver particles and methods for manufacturing the same by J. Yan and Jiachong Cheng

- Nano silver products - A review by Vikas Gupta and Ajay Kumar published in Asian Journal of Biochemical and Pharmaceutical research

- Synthesis and application of Silver Nanoparticles (Ag NPs) for the prevention of infection in healthcare workers by Shingo Nakamura, Masahiro Sato, Tomohiro Takayama and others published in International journal of Molecular sciences published in July 2019

- A report on use of $\mathrm{TiO} 2(\mathrm{~N}) / \mathrm{Ag} / \mathrm{TiO} 2(\mathrm{~N})$ sandwich film coating for instruments exhibit antibacterial, antifungal and antiviral properties by Muhammad Akhsin and Marcel Frommelt

\subsection{Historical Perspective}

Nagarjuna studied the treating of wounds and burns using silver and their alloys. Ancient Indian physician Charaka has written his experience with silver and other minerals in the treatment of various conditions, including improving immunity (ability to fight diseases).

The ayurvedic material medica contains resources in the form of drugs derived from plants, animals, metals and mineral sources against various pathological conditions.

Rajat (as silver is called in Sanskrit) is considered a noble metal like gold as mentioned in Charak Samhita and other Ayurveda experts mentioned using silver foil to cover the food materials to prevent them from spoiling. He also mentioned storing water in silver jars purified it and has a positive effect on the health of the consumer. Charaka recommended the use 
of silver to increase intellect of an individual, increases ability to fight diseases, increases vitality and good for intellect. Silver has been the most studied metal for the purpose of fighting infections and preventing food spoilage right up to the discovery of antibiotics. Prophylaxis against gonococcal ophthalmia neonatorum with silver was considered the gold standard.

\subsection{Properties}

Nano particles are defined as particles with at least one dimension to be less than $100 \mathrm{~nm}$. Their singular physical property (e.g. plasmonic resonance, fluorescent enhancement) and chemical properties (e.g. catalytic activity enhancement) and their ability to affect the biological properties such as ability to attach themselves to viruses and bacteria are of particular interest.

The attachment and entry of viruses into host cells represent an example of multivalent interactions between viral surface components and cell membrane receptors. The ability of nano silver to interfere during this stage makes it a subject of interest for us.

The mode of action of silver is presumed to be dependent on $\mathrm{Ag}+$ ions which strongly inhibit bacterial growth through suppression of respiratory enzymes and elective transport components through interference with DNA/RNA functions of the causative microorganisms and at the same time be nontoxic to the host cells [8]. It is effective against a whole range of bacteria, fungi and viruses and in small quantities not harmful for the host [9].

The microorganisms are unlikely to develop resistance (albeit it is possible for microorganisms to develop resistance) to the nano silver (compared to antibiotics) because silver particles attack a broad range of microbes targets. Silver nano particles have found diverse applications - materials for wound dressing, coating medical devices and textile fabrics. The main advantage of nano silver impregnation is that there is a continuous release of silver ions enhancing its antimicrobial efficacy. The burn wounds treated with nano silver particles show better cosmetic appearance. Nano silver has been shown to be effective against Gram positive and Gram negative microorganisms.

All these above-mentioned properties should be adequately harnessed to create apparel for the surgeons like O.T. gowns, caps, masks and trolley sheets, also providing them with surgical instruments doped with nano silver to ensure the safety of the surgeon and patient [10 - 14].

It is not the scope of this paper to write about the technology of doping and impregnation available in public domain. However, it is the aim of this paper to spread awareness amongst the manufacturers of these products to to use nano silver particles for the manufacturing of these products. It would be ideal to film the naked phaco needle with $\mathrm{TiO} 2(\mathrm{~N}) / \mathrm{Ag} / \mathrm{TiO} 2(\mathrm{~N})$ in such a strong adherent bond. During phacoemulsification, it is natural for some metal particles to dislodge from the needle and settle on the iris tissue and over the pupillary margins.

There are a lot of publications on this topicfor example by
J.J. Martinez - Toldos et al. entitled Metallic fragment deposits during phacoemulsification. The study proves that even if some nano silver particles do get adhered to the ocular tissue they would not cause any harm.

\section{RESULTS}

Traditional medical face masks and gowns use PP MELTBLOWN fabric. The filtration is based on static electricity applied to the fabric by the meltdown process. The efficacy of electrostatic filtration drastically reduces when it comes in contact with moisture. Hence, these masks and gowns are useless for prolonged use or re-use. Moreover the pore diameter of PP meltblown fabric is large enough to let the virus particles pass through them.

Meanwhile, nano PTFE + PP membrane is derived from electrospinning process which filters the air physically. The outer and inner nano silver impregnated layer is washable by soap solutions or ethanol solution thereby making it reusable or usable longer without compromising on its antimicrobial properties.

\section{CONCLUSION}

As we know that the diameter of aerosol carrying virus is bigger than $2.5 \mu \mathrm{m}$ and pore diameter of PTFE + PP membrane is between $0.18 \mu \mathrm{m}$ to $0.5 \mu \mathrm{m}$ the resultant filtration is highly effective.

Cost effectiveness: Nano PTFE+PP membrane is equally cost effective as the traditional meltblown membrane

\section{CONSENT FOR PUBLICATION}

Not applicable.

\section{FUNDING}

None.

\section{CONFLICT OF INTEREST}

The authors declare no conflict of interest, financial or otherwise.

\section{ACKNOWLEDGEMENTS}

Declared none.

\section{REFERENCES}

[1] McDonnell G, Russell AD. Antiseptics and disinfectants: Activity, action, and resistance. Clin Microbiol Rev 1999; 12(1): 147-79. [http://dx.doi.org/10.1128/CMR.12.1.147] [PMID: 9880479]

[2] Liou J W, Chang H H. Bactericidal effects and mechanisms of visible light responsive titanium dioxide photocatalysts on pathogenic bacteria Archivum immunologiae et therapieae experimentalis 2012;60: 267-75.

[3] Linsebigler AL. Lu, G. Yates, J. T. Photocatalysis on TiO2 surfaces: Principles, mechanisms and selected results. Chem Rev 1995; 95: 735-58.

[http://dx.doi.org/10.1021/cr00035a013]

[4] Wong MS, Sun D S, Chang H H. Bactericidal performance of visible light responsive titania photocatalyst with silver nano structures. PLoS One 2010; 5: e10394.

[5] Wong MS, Chu WC, Sun DS, et al. Visible-light-induced bactericidal activity of a nitrogen-doped titanium photocatalyst against human pathogens. Appl Environ Microbiol 2006; 72(9): 6111-6. [http://dx.doi.org/10.1128/AEM.02580-05] [PMID: 16957236] 
[6] Dhar A, Alford T L. High quality transparent $\mathrm{TiO} 2 / \mathrm{Ag} / \mathrm{TiO} 2$ composite electrode films deposited on flexible substrate at room temperature by sputtering APL Materials 2013; 1 ID: 012102

[7] Silver S. Bacterial silver resistance: Molecular biology and uses and misuses of silver compounds. FEMS Microbiol Rev 2003; 27(2-3): 341-53.

[http://dx.doi.org/10.1016/S0168-6445(03)00047-0]

[PMID: 12829274]

[8] Liga MV. El Bryant, Colvin, V. L. Virus inactivation by silver doped titanium dioxide nano particles for drinking water treatment. Water Res 2011.

[http://dx.doi.org/10.1016/j.watres.2010.09.012]

[9] . Galdiero Stefania, Annarita Falanga et al. Silver nanoparticles as potential antiviral agents

[10] Falanga A, Vitiello MT, Cantisani M. A peptide derived from Herpes simplex type 1 glycoprotein H. Nanomedicine (Lond) 2011 [http://dx.doi.org/10.1016/j.nano.2011.04.009] [PMID: 21664490]

[11] Yasutaka Mori, Takeshi Ono et al. Antiviral activity of silver nanoparticles/chitosan composites against $\mathrm{H} 1 \mathrm{~N} 1$ influenza A virus

[12] Elechiguerra JL, Burt JL, Morones JR, et al. Interaction of silver nanoparticles with HIV-1. J Nanobiotechnology 2005; 3: 6. [http://dx.doi.org/10.1186/1477-3155-3-6] [PMID: 15987516]

[13] Lu L, Sun RW, Chen R, et al. Silver nanoparticles inhibit hepatitis B virus replication. Antivir Ther 2008; 13(2): 253-62. [PMID: 18505176]

[14] Baram-Pinto D, Shukla S, Perkas N, Gedanken A, Sarid R. Inhibition of herpes simplex virus type 1 infection by silver nanoparticles capped with mercaptoethane sulfonate. Bioconjug Chem 2009; 20(8): 1497-502.

[http://dx.doi.org/10.1021/bc900215b] [PMID: 21141805]

\section{C) 2021 Dnyanmote et al.}

This is an open access article distributed under the terms of the Creative Commons Attribution 4.0 International Public License (CC-BY 4.0), a copy of which is available at: https://creativecommons.org/licenses/by/4.0/legalcode. This license permits unrestricted use, distribution, and reproduction in any medium, provided the original author and source are credited. 